\title{
Prototyping of Flooding Early Warning System using Internet of Things Technology and Social Media
}

\author{
Aris Haris Rismayana ${ }^{1, *}$, Castaka Agus Sugianto ${ }^{1}$, and Ida Bagus Budiyanto ${ }^{1}$ \\ ${ }^{1}$ Politeknik TEDC Bandung, Jl. Pesantren Km 2 Cibabat - Cimahi Utara 40513 Cimahi - Jawa Barat - Indonesia
}

\begin{abstract}
When the rainy season arrives, flooding is a common phenomenon. Almost every street, housing, village, river, even in the city center, wherever floods can occur. One effort to prevent the flooding is to create a floodgate on reservoirs or dams that are used to control the water distribution. The water level at this dam must be checked frequently to anticipate if the water level is at a dangerous level. The inspection of water levels will be very difficult if it must be conducted by humans who must be available in the field at any time. This research aims to create a prototype system that can replace the human role in monitoring the dam water level condition at any time by developing an integrated system between hardware and software using IoT (Internet of Things) technology approach and social media (twitter and telegram). The developed system consists of the height sensor (distance), microcontroller and wifi module, which is placed on the water gate. This system serves to measure the water level at any time and send data in real time to the server. The results of system testing performed shows that when the system is in normal circumstances, the system sends data to the server every minute, and updates the status of water level in twitter every 5 minutes. In case the water level has exceeded a predetermined limit, the system sends data to the server every 5 seconds and passes the warning message to all registered telegram contacts.
\end{abstract}

\section{Introduction}

Flooding is a phenomenon that occurs when the water that flows exceeds its flow capacity, floods can occur anywhere either in the river, road, housing, even downtown as well as this problem. High water flooding will not be a problem when it does not cause loss of property, human life, and does not soak the settlement of citizens for a long time. However, when overflow of large volumes of water occurs for a long time and often this can disrupt the activities of the people living in the area. This is a problem, this flood disaster is not only disrupt the activities of the people, even the effects further impact to social and economic development, even dangerous of human life [1]. This flood disaster could not be eliminated, but the problems that arise from this flood could be reduced by the system that capable of providing an early warning flood. The system is easily accessed by peoples using common messaging media such as telegram and social media such as twitter. This system is also accessible both of peoples that directly affected by floods and the relevant government as a decision maker.

According to the Indonesian National Disaster Management Agency in disaster data during the period of 1815-2010 the flood disaster has the largest frequency, which is $36 \%$. The area and frequency of the flood are increasing with increasing of losses [2][3]. With this condition, the efforts are needed to prevent it. The key to success, in reducing the loss of property and life caused by floods, is to provide information or early warning to nearby residents to perform some actions such as evacuation, contingency planning and so on [4]. One of the prevention efforts is to create a water gate in the reservoir or dam that serves to control the water distribution. Monitoring of water levels in dams should often be done to anticipate if water levels are at dangerous levels, the action can be taken immediately to address them. Monitoring of water level, if it must be done by humans will be very difficult because they must be available in the field at any time.

Several studies have been done to overcome this flood disaster, one of them Bando et.al. where the results are displayed on the web [5][6]. Meanwhile, Mokh Sholihul Hadi et.al. developed flood detection devices and Electric circuit breaker for home protection when floods occur [7]. Other researchers created a flood early warning system using SMS [8][9][10][11][12]. In addition, some use datamining technology in dealing with flood by forecasting, such as research using SVR Method optimized using TVIWPSO method is used to find the best particle to be used as a reference in forecasting [13].

This study aims to create a prototype system that can replace the human role in monitoring of the dam water level conditions at all times by developing an integrated system of hardware and software using the IoT (Internet of Things) technology approach and social media (twitter and telegram).

\footnotetext{
* Corresponding author: rismayana@poltektedc.ac.id
} 


\section{Methodology}

This project is based on flowchart in Fig 1. Initial Feasibility and Problem Definition was done to check whether the project was able to fulfill the objective to give an early warning water level in real time. After that, find a literature as a supporter or a comparison against the project made. Then build hardware (HW) and also firmware microcontroller (FW) for data acquisition. Once it is done, then tested about the accuracy of the data obtained, and also seen whether the data is saved to the server. After the data has been saved to the server, then build the application software which consists of 2 parts, Telegram Bot and Twitter API. Once it is completed then each application is tested. For telegram bots tested with water level requests, and warning notification tests when water levels have exceeded predetermined limits. For testing the Twitter API, it should be seen on twitter account that has been set to post a water level every 5 minute.

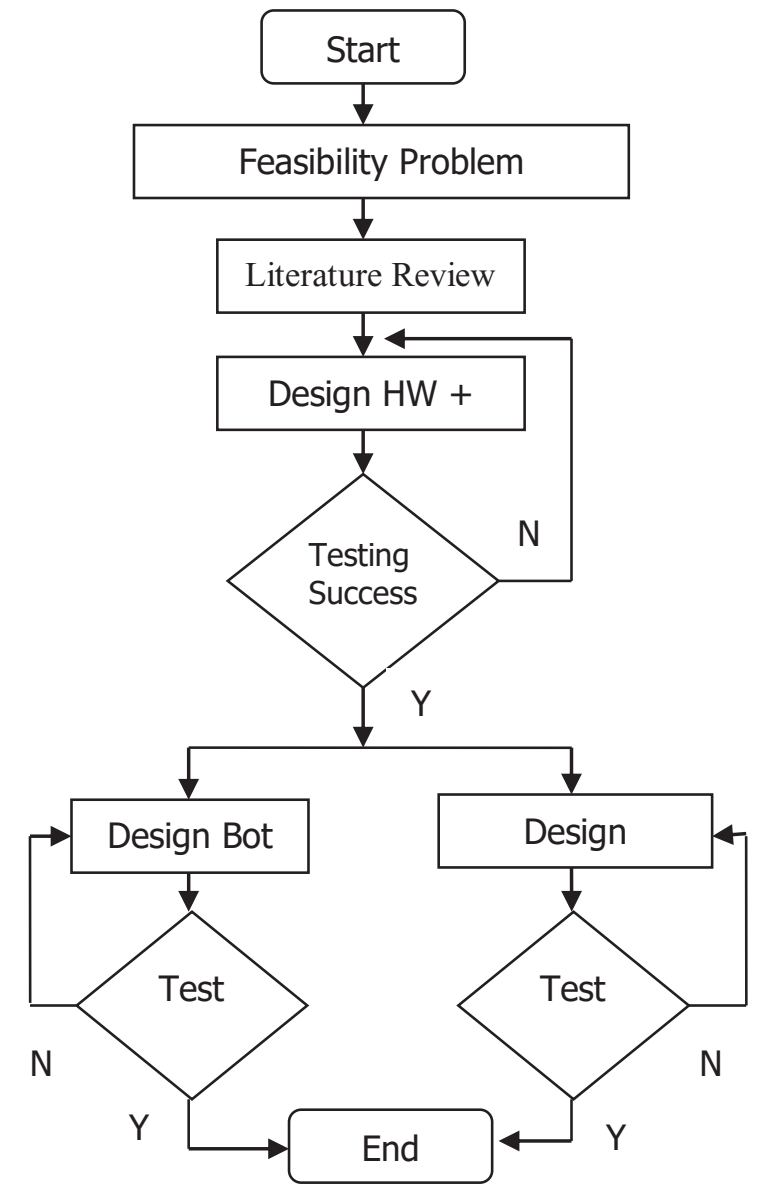

Fig. 1. Methodology.

\section{System design}

The system model is described in figure 2, which consists of 3 main parts: Data acquisition and data transmission, data processing for twitter applications, data processing for telegram applications

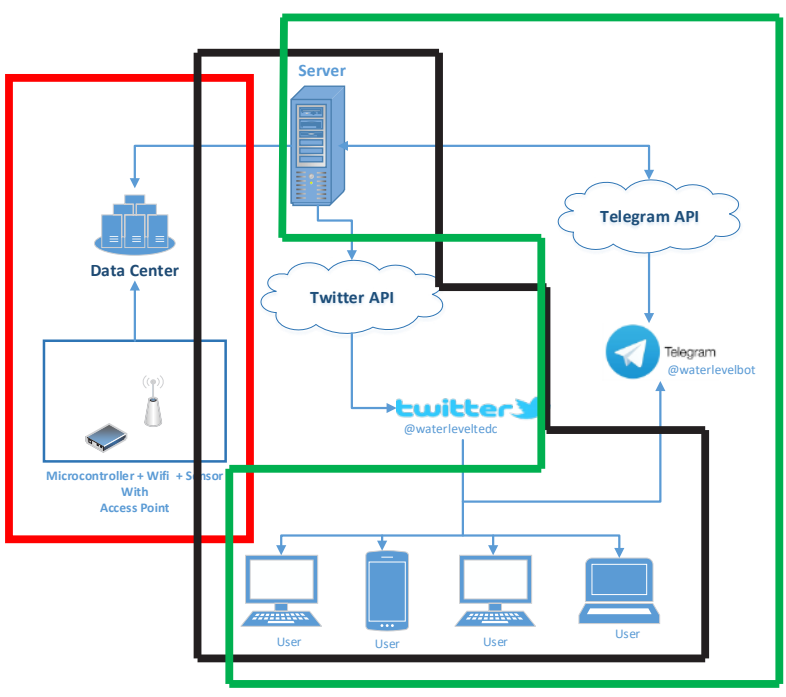

Fig. 2. System Model

\subsection{Data acquisition and data transmission}

In the process of acquisition and transmission of data required several components are as follows (1) Microcontroller + Wifi Module, (2) Ultrasonic Sensor, (3) Access Point, (4) Server Hosting (Data Center) and (5) API.

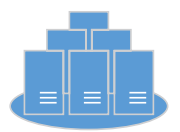

Data Center

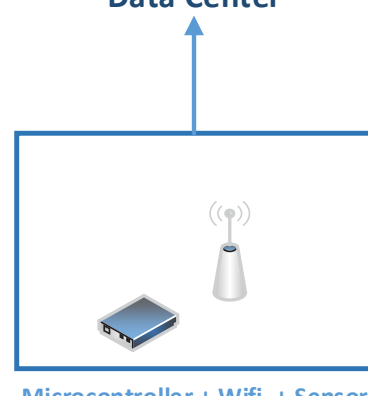

Microcontroller + Wifi + Sensor

With

Access Point

Fig. 3. Data acquisition and data transmission.

Figure 3 explains the sensor installed on the microcontroller periodically checks the water level, then sends it to the server. The data transmitted is the height data (in $\mathrm{cm}$ ) and the time at which the data is sampled. Under normal conditions (water level within reasonable limits), the device sends data to the server every minute. Under alert conditions (the water level reaches the specified maximum), the device sends data to the server every 10 seconds

\subsection{Data processing for twitter applications}

In this process required several components are as follows:

- Using the twitter API

- Using NodeJS programming language

- Hosting/Server data center 
- Follow twitter account at @WaterLevelTEDC

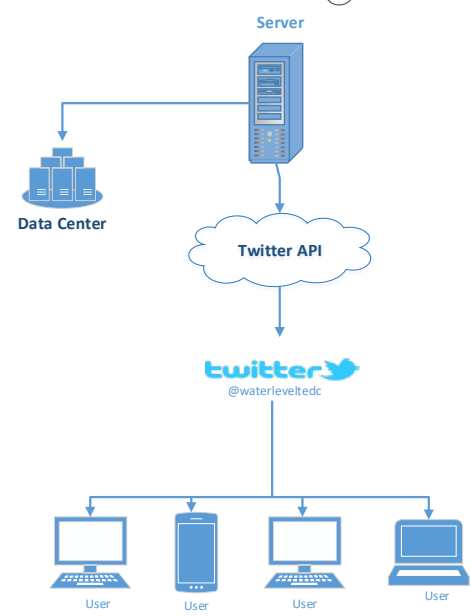

Fig. 4. Data processing for twitter applications.

Figure 4 explains twitter application created using NodeJS as the programming language. The application is passive, just posting height and time sampling information only. This twitter application post periodically every 5 minutes. Every 5 minutes, the app checks to the server, then retrieves the last 1 entry data entry

\subsection{Data processing for telegram applications}

In this process required several components are as follows:

- Using the telegram bot API

- Using C \# programming languages

- Hosting/server data center

- Telegram bot: @WaterLevelBot

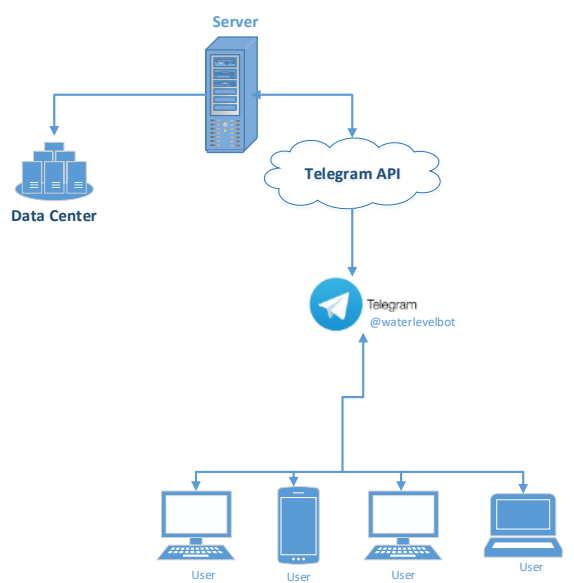

Fig. 5. Data processing for telegram applications.

Figure 5 explains telegram Bot created using C \# programming language, this telegram bot application is active, by request and alert notifications telegram bot Features:

- $\quad$ Check the current water level, keyword: /level

- Checking the water level of some recent data, keyword: /level xx (where $\mathrm{xx}$ is the number of data requested)
- Register to get alert notification (if the water level reaches the maximum limit), keyword: /reg

- Register to disable alert notifications, keyword: /unreg

The bot app checks the server every second to see if there is an alert, if there is an alert, then the bot app will send a warning message to the user who has registered.

\section{Results and discussion}

The flood disasters prevention should be comprehensive and involve various parties, especially governments and peoples that directly affected by floods. For prevention, flood information could be acquire using SMS media [8] [9][10][11][12] or using Internet Of Things (IoT) Technology[12][14][15]. But the evolution of technology rigth now, SMS is rarely used, changed to messaging media like Whatsapp, LINE or Telegram. Similarly, the evolution of social media, such as twitter or facebook as a source of information is faster than the television or newspaper.

Therefore, in this research we built a system that make an early warning flood using telegram messaging media and social media twitter as a giver of information about water level.

In twitter application, we can see the results of monitoring the height of water obtained from the tool. To view the status on twitter, we should follow the @)WaterLevelTEDC twitter account. The account shows the water level status every five minutes. As shown in Figure 6.

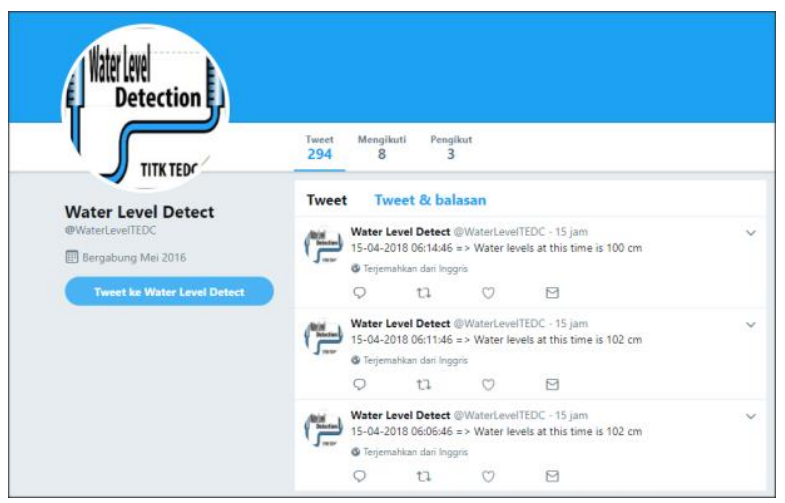

Fig. 6. Information on Twitter water level.

For telegram applications, users who want to interact with telegram bots must first add this water level bot. The bots name is @WaterLevelBot. 


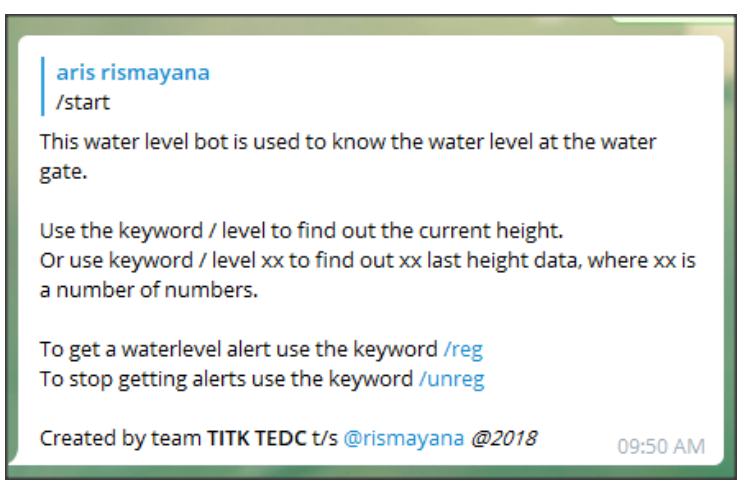

Fig. 7. Start bot telegram water level.

Figure 7 shows the first telegram display, when we start following the@WaterLevelBot telegram bot. In normal conditions, if the user wants to know the current water level, use the keyword /level, as shown in the image below.

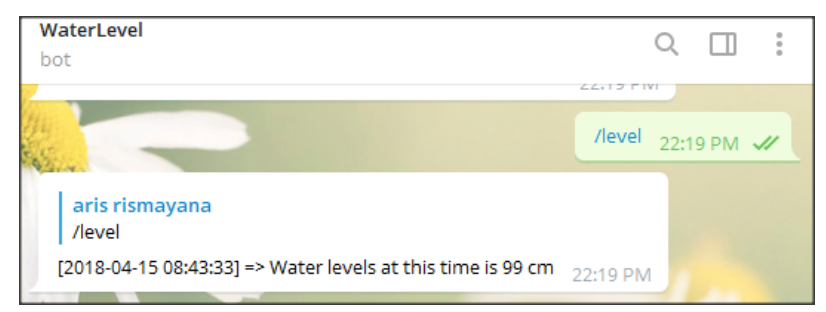

Fig. 8. Request last water level.

We can see in figure 8 , the system (bot) sends the last water level recorded by the data center. However, if we want to see some last water level data, we can use the keyword /level + amount of data we want, here's an example to get the last 8 data, the keyword is /level 8 .

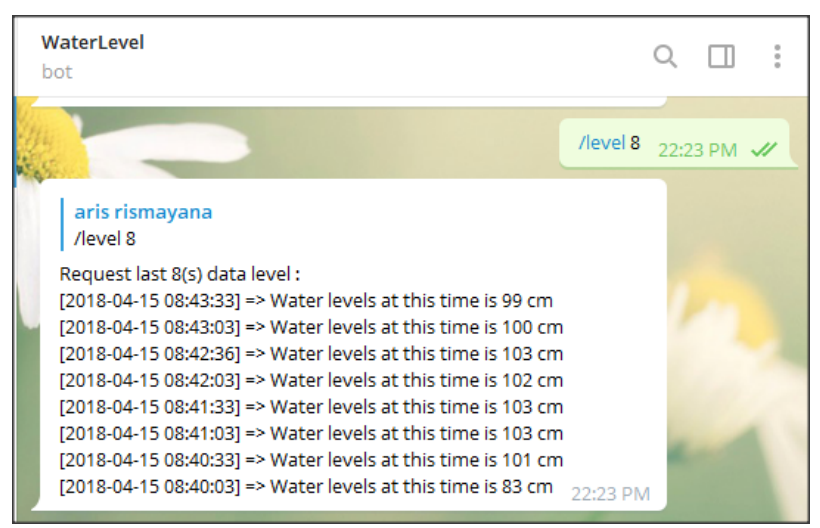

Fig. 9. Request some of water level data.

In Figure 9 shown, the $@$ WaterLevelBot bot sends the last 8 data as requested by the user. Then if the user wants to get an alert message, the message will be obtained if the water level has exceeded the maximum height that has been set, then can use the keyword/reg.

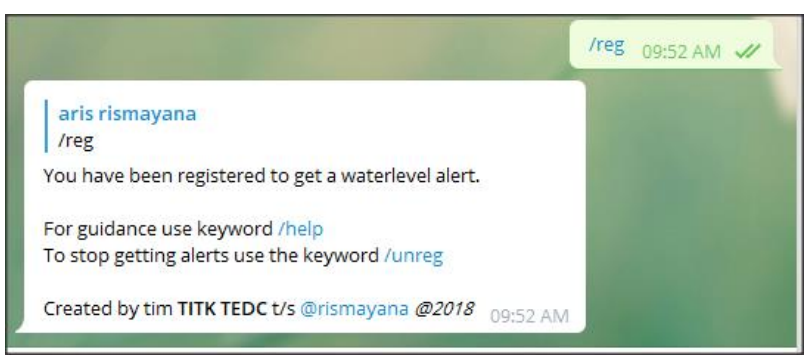

Fig. 10. Register to bot telegram.

If the user has registered as shown in Figure 10, then user will get alert notification as shown in picture 11 below.

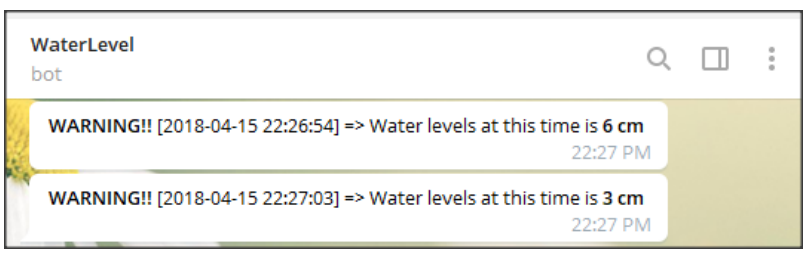

Fig. 11. Alert of water level data.

The alert message is obtained as long as the water level remains above normal. And, if the user wants to stop getting alert notifications, then use the keyword /unreg as seen in Figure 12.

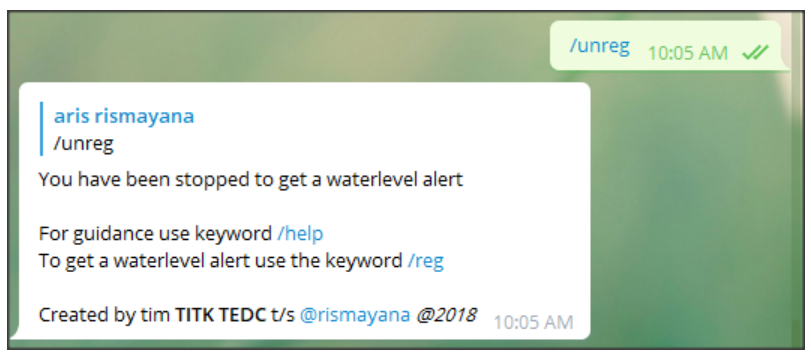

Fig. 12. Unregister to bot telegram.

\section{Conclusion}

This study from the last testing results, it is evident that the system successfully serves to measure the water level at any time and send data in real time to the server. In normal condition, the system sends data to the server every minute, and updates the state of water level in twitter every 5 minutes. In case the water level has exceeded a predetermined limit, the system sends data to the server every 5 seconds and passes the warning message to all registered telegram contacts.

From this study has provided an avenue for the researcher to conduct future works in this research topic are: (1) IIS (Integrated Information System) Integrated approach to floods early-warning based on geoinformatics

- remote sensing $(\mathrm{RS})$,

- geographical information systems (GIS)

- global positioning systems (GPS)

(2) It consists of main components such as infrastructure and devices in IoT, cloud information warehouse, management tools, applications and services, 
the results from a case study shows that the effectiveness of flood prediction and decision-making can be improved by using the IIS

\section{References}

1. H. Tai, A. Celesti, M. Fazio, M. Villari, A. Puliafito, An Integrated System for Advanced Water Risk Management Based on Cloud Computing and IoT, 2nd World Symposium on Web Application and Networking, 1-7 (2015)

2. T. Triyono, K. Kurniah, N. Andriana, T. Kusumawati, N. Hardianto, Guidelines for Preparednes Earthquake and Tsunami Community based, National Board for Disaster Management (2014)

3. S. Ginting, W. M. Putuhena, Jakarata Flood Early Warning System, Journal Water Resour., 10, 1, 7184 (2014)

4. T. Perumal, N. Sulaiman, C. Y. Leong, Internet of Things ( IoT ) Enabled Water Monitoring System, 4th Global Conference on Consumer Electronics, 86-87 (2015)

5. S. A. Bondo, D. Darlis, S. Aulia, Implementation device detection flooding in Permata Buah Batu housing with technology Internet of Things (IoT), J. E-Proceeding Appl. Sci., 2, 3, 1376-1383 (2016)

6. G. Y. Purnomo and C. Dewi, Design of Early Flood Detection System Using the Concept Internet Of Things (2017)

7. M. S. Hadi, D. A. Tricahyo, D. K. Sandy, F. S. Wibowo, IOT Cloud Data Loger for Early Flood Disaster Detection System on Integrated Social Media Settlements, J. Electr. Educ., 1, 2, 129-133 (2017)

8. W. A. H. W. M. Asmara, N. H. A. Aziz, SMS Flood Alert System, Control and System Graduate Research Colloquium, 18-22 (2011)

9. E. Kuantama, L. Setyawan, J. Darma, Early Flood Alerts Using Short Message Service (SMS), International Conference on system Engineering and Technology, 3-7 (2012)

10. H. N. Do, M. Vo, V. Tran, P. V. Tan, C. V. Trinh, An Early Flood Detection System Using Mobile Networks, International Conference on Advanced Technology for Cimmunications (ATC), 599-603 (2015)

11. M. S. Baharum, R. A. Awang, N. H. Baba, Flood Monitoring System ( MyFMS ), International Conference on System Engineering and Technology, 204-208 (2011)

12. A. K. V, B. Girish, K. R. Rajesh, Integrated Weather \& Flood Alerting System, Int. Adv. Res. J. Sci. Eng. Technol., 2, 6, 21-24 (2015)

13. A. A. Soebroto, I. Cholissodin, R. C. Wihandika, M. T. Frestantiya, E. Arief, Prediction of Water Level for Early Detection of Flood Disaster Using SVR-TVIWPSO, J. Inf. Technol. Comput. Sci., 2, 2, 79-86 (2015)

14. M. Salunke, N. Korade, Survey on Flooding Detection System using Internet of Things, Int. J.
Comput. Appl., 165, 13, 14-16 (2017)

15. D. Satria, S. Yana, R. Munadi, S. Syahreza, Prototype of Google Maps-Based Flood Monitoring System Using Arduino and GSM Module, Int. Res. J. Eng. Technol., 4, 10, 1044-1047 (2017) 